\title{
COMPROMISO OSEO EN HISTIOCITOSIS DE CELULAS DE LANGERHANS EN EL NIÑO. ESTUDIO RADIOLOGICO SIMPLE. PRESENTACION CLINICA Y DIAGNOSTICO RADIOLOGICO
}

\author{
Drs. Raúl Rojas $C^{(1)}$, Cristián García $B^{(1,2)}$, Dimitri Parra $R^{(1)}$, Antonieta Solar $\mathbf{G}^{(3)}$, Roberto Oyanedel $Q^{(1)}$, Fernán \\ Díaz $B^{(1)}(t)$, Juan Fortune $H^{(4)}$, Martín Etchart $K^{(3)}$. \\ 1. Departamento de Radiología. Facultad de Medicina, Pontificia Universidad Católica de Chile. \\ 2. Departamento de Pediatría. Facultad de Medicina, Pontificia Universidad Católica de Chile. \\ 3. Departamento de Anatomía Patológica. Facultad de Medicina, Pontificia Universidad Católica de Chile. \\ 4. Departamento de Traumatología. Facultad de Medicina, Pontificia Universidad Católica de Chile.
}

\begin{abstract}
Introduction. Langerhans' cell histiocytosis is an uncommon disease, with various radiological presentations. Its cause remains unknown, with the pathological hallmark being proliferation of Langerhans' cells. The spectrum of disease ranges from solitary bone lesions to multisystemic affection. Usually, the first diagnostic test performed is the plain radiograph, and the radiological findings may be hard to analyze. Differential diagnosis should include osteomyelitis, Ewing's sarcoma and lymphoma. Objectives: To show the plain radiographic findings of $\mathrm{LCH}$, that allow the radiologist to suspect it. Methods and materials: The clinical and radiological presentations of the biopsy proven $\mathrm{LCH}$ cases of the National Bone Tumor File (RENATO) between the years 1961 and 1999 were analyzed retrospectively. Results: From a total of 59 patients, $58 \%$ were boys and $42 \%$ were girls. Age ranged from 0.8 to 17 years, with an average of 6.1 years. Medical history was obtained in 56 cases (95\%). The mean duration of symptoms at diagnosis was 5,5 months, with pain at the site of affection being the most frequent 50/59 of them. Forty-eigth patients (81\%) presented with a solitary bone lesion and 11 (19\%) presented with two or more lesions; 35 patients had afection of long bones and 26 of axial skeleton. The most frequently radiological pattern was a purely osteolytic lesion $(n=45) .13$ patients presented with a permeative lesion and a vertebra plana was found in 3. Periostal reaction and soft tissue mass were found in 30 and
\end{abstract}

Rojas $\boldsymbol{R}, \boldsymbol{y}$ cols. Compromiso óseo en histiocitosis de células de Langerhans en el niño. Estudio radiológico simple. Presentacion clínica y diagnóstico radiológico. Rev Chil Radiol 2005; 11: 122- 128.

Correspondencia: Dr. Cristián García B.

E-mail:cgarcia@med.puc.cl
29 cases respectively. Conclusions: Despite the fact that $L C H$ has several radiological manifestations, its diagnosis should be suspected by the radiologist. This study with biopsy proven cases of Langerhans' cell histiocytosis allows us to characterize the manifestations of this disease in the skeleton and is useful for the differential diagnosis of a bone lesion in the pediatric patient.

Keywords: Eosinophilic granuloma, Histiocytosis X, Langerhans' cell histiocytosis.

Resumen: Introducción. La Histiocitosis de células de Langerhans (HCL) es una patología poco frecuente, con diferentes manifestaciones radiológicas. Su causa es desconocida y se caracteriza por una proliferación de las células de Langerhans. Sus manifestaciones varían desde lesiones óseas aisladas hasta el compromiso sistémico. Muchas veces el primer estudio diagnóstico corresponde a la radiografía simple de la zona afectada y sus hallazgos pueden ser difíciles de interpretar. El diagnóstico diferencial debe incluir fundamentalmente osteomielitis, sarcoma de Ewing y linfoma. Objetivos: Mostrar las manifestaciones radiológicas de la HCL, que permiten al radiólogo sospechar el diagnóstico. Material y métodos: Análisis retrospectivo de las manifestaciones clínicas y radiológicas en los casos de HCL confirmados con histología, que forman parte del Registro Nacional de Tumores Oseos (RENATO) y que fueron incorporados a éste entre los años 1959 y 1999. Resultados: Se obtuvo un total de 59 pacientes, 34 (58\%) varones y 25 (42\%) niñas en quienes el estudio histológico fue compatible con el diagnóstico de HCL. El rango de edad varió desde 0.8 hasta 17 años (promedio 6.1 años). Se tuvo acceso a las historias clínicas en 56 de los casos. El tiempo 
promedio de duración de los síntomas fue de 5,5 meses, y el motivo de consulta más frecuente fue dolor del sitio afectado $(n=50)$. Del total, $48(81 \%)$ presentaron lesión ósea única y 11 (19\%) dos o más lesiones. En 35 pacientes hubo compromiso de huesos largos y en 26, del esqueleto axial. El patrón radiológico predominante fue el de una lesión osteolítica pura (45 pacientes). En 13 pacientes se observó un patrón permeativo y 3 se presentaron con una vértebra plana. En 30 había reacción perióstica y 29 tenían aumento de volumen de las partes blandas vecinas. Conclusiones: El patrón de presentación radiológica de la HCL es variado, sin embargo su diagnóstico debe ser sospechado por el médico radiólogo. Esta revisión, permite caracterizar las manifestaciones óseas de esta enfermedad y es de utilidad en el enfrentamiento $y$ en el diagnóstico diferencial de una lesión ósea en el paciente pediátrico.

Palabras clave: Granuloma eosinófilo, Histiocitosis de células de Langerhans, Histiocitosis.

\section{Introducción}

La Histiocitosis de células de Langerhans ( $\mathrm{HCL}$ ) es una patología poco frecuente, caracterizada por proliferación de este tipo celular, y su compromiso puede ser local o sistémico. Ocurre habitualmente antes de los 15 años, existiendo una ligera predilección por el sexo masculino(1). Su espectro de manifestaciones clínicas y radiológicas es amplio y puede presentar características sugerentes de un proceso infeccioso o de un tumor benigno o maligno. La forma de presentación más común es el compromiso óseo, por lo que es importante reconocer sus manifestaciones.

Las tres formas clásicas de la HCL son la Enfermedad de Letterer-Siwe que es la forma aguda, diseminada, con compromiso multisistémico, altamente letal, la Enfermedad de Hand-SchüllerChristian la forma crónica, con la tríada clásica de lesiones craneanas, exoftalmos y diabetes insípida y el granuloma eosinófilo o forma localizada en el hueso y/o pulmón ${ }^{(2-4)}$. Todas ellas tienen en común la proliferación idiopática de histiocitos y producen manifestaciones localizadas y sistémicas.

El término Histiocitosis de Langerhans se aceptó en 1987, tras la realización de estudios que identificaron la célula de Langerhans como el histiocito distintivo en las lesiones activas(5).

La patogénesis de la enfermedad no es bien conocida. Se han postulado como factores causales, un agente infeccioso(6), un factor genético, metabólico, una asociación con inmunodeficiencias, o un proceso neoplásico ${ }^{(7)}$. Recientemente se han descubierto alteraciones inmunológicas en pacientes con HCL, lo que ha llevado al concepto actual de un trastorno en la respuesta inmune ${ }^{(8)}$.
En series extranjeras, la HCL representa menos del $1 \%$ de las lesiones óseas primarias biopsiadas $^{(8)}$. Las manifestaciones histopatológicas varían según el órgano afectado y la etapa de la enfermedad. Todas las formas tienen en común la proliferación de células de Langerhans, las cuales forman granulomas junto a linfocitos, macrófagos y eosinófilos $^{(9)}$, aun cuando la presencia de estos últimos no es necesaria para el diagnóstico. Históricamente, el diagnóstico definitivo se realizaba con microscopía electrónica, demostrando gránulos de Birbeck al interior del citoplasma. Las células de Langerhans también expresan el antígeno de superficie T6, y son positivas para la tinción inmunohistoquímica para la proteína S-100. Dado que la inmunohistoquímica está actualmente más disponible y es de menor costo, ha sido la más usada en los últimos 5 años ${ }^{(10)}$.

Clínicamente, la forma localizada da cuenta de aproximadamente el $80 \%$ de todos los casos en el niño, hasta en un $90 \%$ ocurre en el hueso y es la forma menos agresiva y con mejor pronóstico. Tiene predominio por el sexo masculino, con una razón aproximada de $2: 1$. Cerca del $90 \%$ de los pacientes con compromiso esquelético localizado debutan entre los 5 y 15 años de edad.

Las manifestaciones clínicas dependen del hueso comprometido, siendo lo habitual el dolor local, sensibilidad y aumento de volumen. Es común la otitis crónica en el compromiso mastoídeo, que puede tener como consecuencia la pérdida de la audición ${ }^{(11)}$. El compromiso espinal puede producir deformidades, dolor, rigidez y complicaciones neurológicas, lo que es inhabitual(12). La mayoría de los pacientes presentan síntomas con menos de dos meses de evolución, aunque las lesiones pueden ser clínicamente silenciosas. Es frecuente la confusión con infección, ya que puede haber fiebre de bajo grado, aumento de la VHS, leucocitosis leve y anemia normocítica normocrómica. Aproximadamente el $10 \%$ de los pacientes con HCL ósea solitaria puede desarrollar eventualmente una forma multifocal y extraósea.

Desde el punto de vista del diagnóstico, la radiografía $(\mathrm{Rx})$ simple es generalmente el estudio inicial, y los hallazgos pueden ser difíciles de interpretar aun cuando es habitualmente la mejor manera de evaluar el compromiso esquelético. El patrón radiológico depende del hueso afectado y de la fase de la enfermedad ${ }^{(8)}$. Las lesiones agudas son generalmente osteolíticas, con bordes mal definidos y puede ser difícil diferenciarlas de una osteomielitis, sarcoma de Ewing o linfoma. En huesos largos, el hallazgo inicial suele ser el de una pequeña lesión osteolítica, que puede progresar hacia la etapa crónica, con erosión de la cortical, reacción perióstica y/o aumento de volumen de partes blandas ${ }^{(8,10)}$. 
El propósito de este trabajo es mostrar las manifestaciones en radiología simple de la HCL ósea en niños, que debieran permitir al radiólogo sospechar su diagnóstico.

\section{Material y métodos}

Se analizaron retrospectivamente las manifestaciones clínicas y radiológicas de los casos pediátricos de HCL confirmados con histología, que forman parte del Registro Nacional de Tumores Óseos (RENATO) y que fueron incorporados a éste entre los años 1959 y 1999.

\section{Resultados}

De un total de 59 pacientes, 34 (58\%) eran varones y 25 (42\%) niñas, con un predominio masculino de 1,4:1 y con un rango de edad desde 9 meses hasta 17 años (promedio 6.1 años). En 56 casos se tuvo acceso a la historia clínica.

El tiempo promedio de evolución de los síntomas al momento del diagnóstico fue de 5,5 meses. Las manifestaciones clínicas se resumen en la Tabla I. Del total, $46(78 \%)$ presentaron lesión ósea única y 13 (22\%) tuvieron dos o más lesiones. En 36 pacientes hubo compromiso de huesos largos de extremidades y en 28 del esqueleto axial, siendo el hueso más frecuentemente comprometido el fémur $(33 \%)$, seguido por el cráneo $(17 \%)$ y los huesos pélvicos (15\%). La ubicación de las lesiones se resume en la figura 1.

\begin{tabular}{|lc|}
\hline \multicolumn{2}{|l|}{ Tabla I. Manifestaciones clínicas de HCL. } \\
SINTOMA & $\%$ \\
\hline Dolor local & 89,3 \\
Aumento de volumen & 35,7 \\
Impotencia funcional & 32,1 \\
Síntomas constitucionales & 14,3 \\
Traumatismo mínimo & 16,1 \\
\hline
\end{tabular}

El patrón radiológico predominante fue el de una lesión lítica pura (45 pacientes) (Figuras 2-4). En el cráneo el patrón encontrado fue el de una lesión osteolítica, de contornos irregulares. (Figuras 3 y 4 ). En 13 pacientes se observó un patrón permeativo (Figura 2 y 3), en 30 había reacción perióstica (Figuras 5-7) y 29 tenían aumento de volumen de las partes blandas adyacentes. El patrón radiológico observado en los tres pacientes con compromiso de columna fue el de vértebra plana (Figura 8). En los huesos largos el patrón predominante fue también de una lesión osteolítica, aunque se observó un patrón permeativo en alrededor de un tercio de los pacientes.

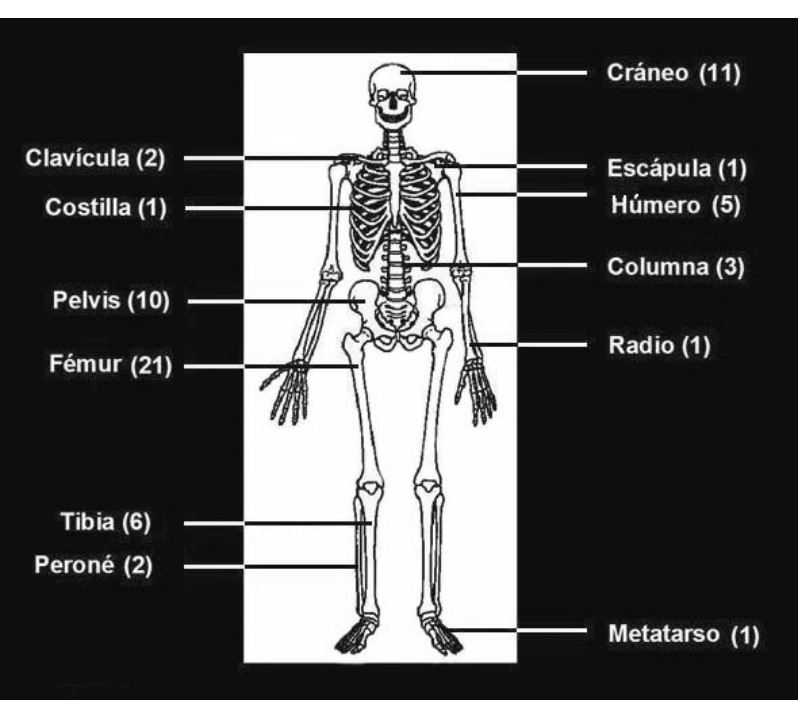

Figura 1. Localización de las lesiones óseas de la HCL. Los sitios más afectados fueron el fémur, cráneo y los huesos pelvianos.

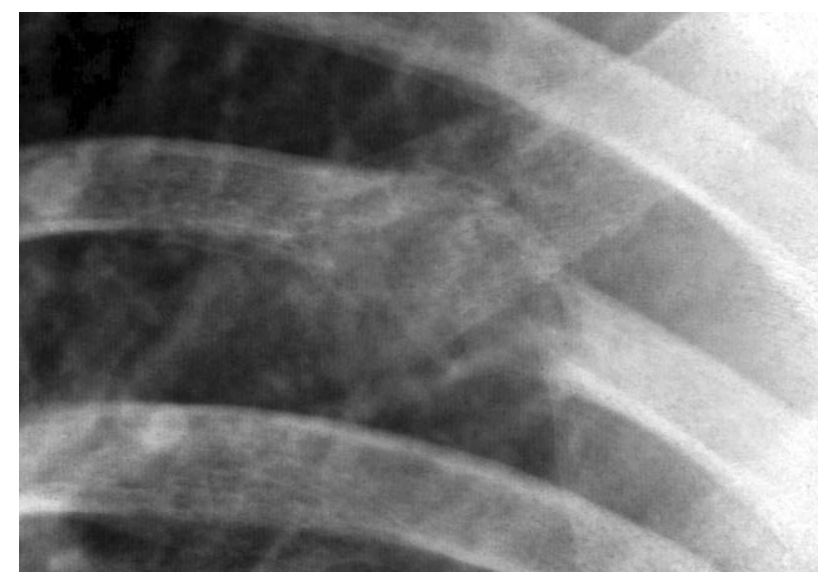

Figura 2. Lesión osteolítica de costilla, de aspecto permeativo.

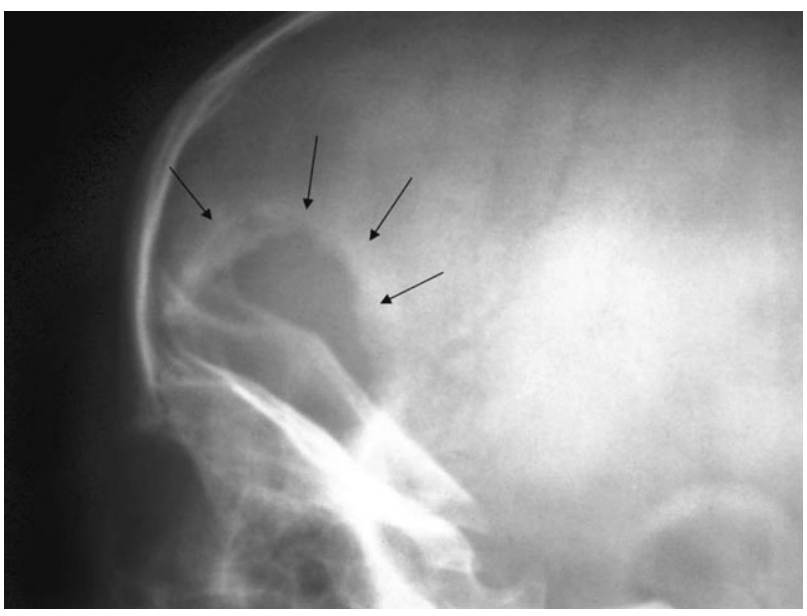

Figura 3. Radiografía lateral de cráneo de un niño de 3 años con aumento de volumen y dolor de la región ciliar derecha muestra una lesión osteolítica de contornos irregulares. 


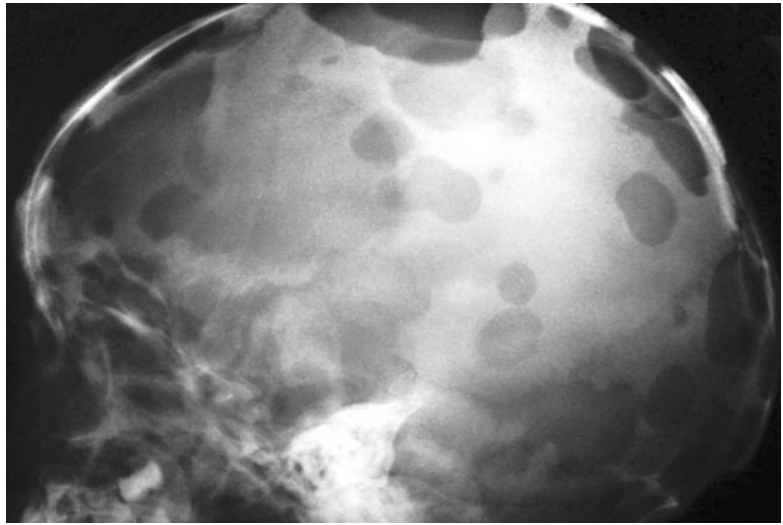

Figura 4. Radiografía lateral de cráneo de un niño de 5 años con Enfermedad de Hand-Schuller-Christian muestra múltiples lesiones osteolíticas, algunas de ellas confluentes, lo que determina en algunas un contorno geográfico.
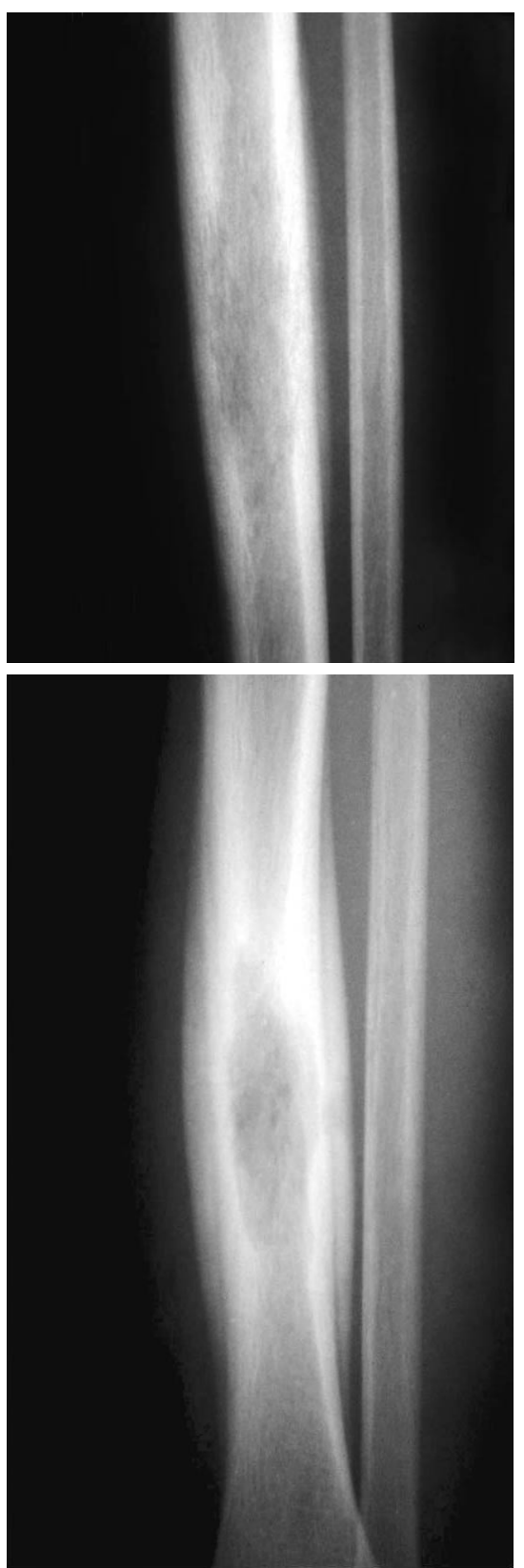

Figura 5. HCL.

Patrón

permeativo.

Radiografía $A P$ de pierna

muestra un

aspecto

"apolillado" del

tercio medio de

la diáfisis tibial,

asociado a

reacción

perióstica.

\section{Figura 6.}

Compromiso en

huesos largos.

Radiografía AP de

pierna que muestra

una lesión lítica

expansiva, de

bordes bien

definidos, asociada

a reacción

perióstica sólida.

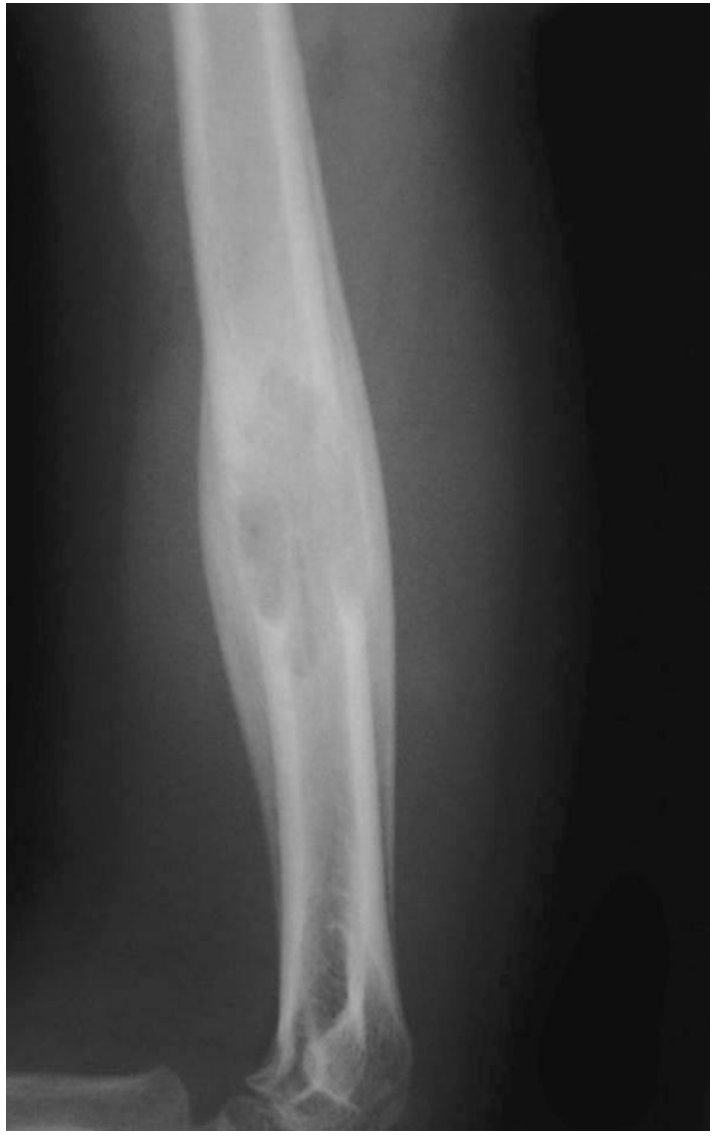

Figura 7. Compromiso en huesos largos. Radiografía lateral de húmero muestra una lesión lítica expansiva, con reacción perióstica.

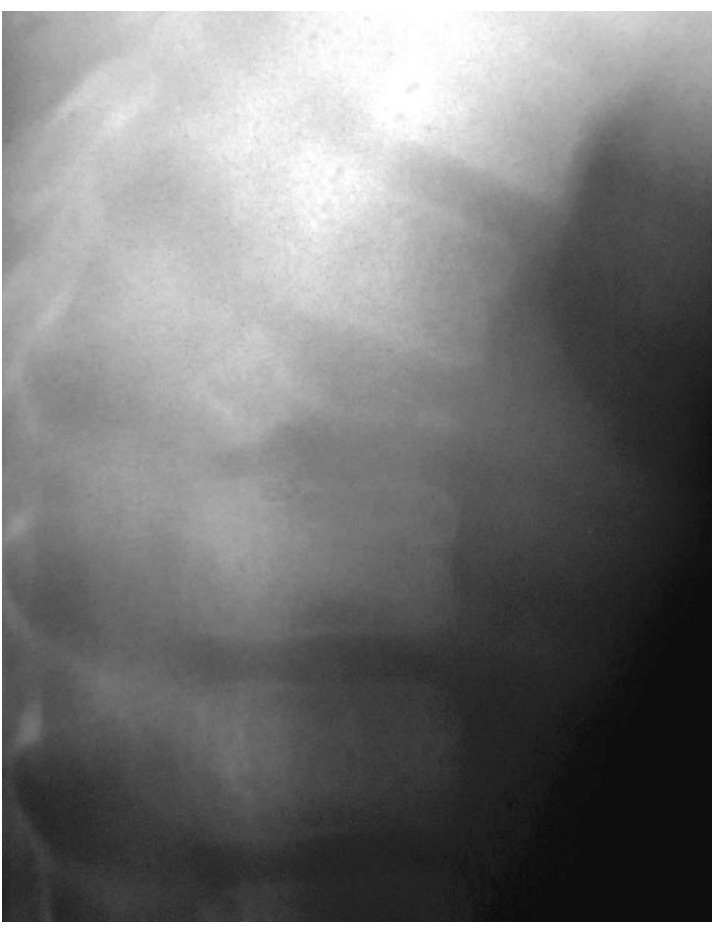

Figura 8. Radiografía lateral de columna dorsal muestra una vértebra plana. 
en la Tabla II.

Las manifestaciones radiológicas se resumen

El estudio anatomopatológico fue diagnóstico para HCL en todos los pacientes. Con tinción de hematoxilina-eosina, se observó proliferación de células de Langerhans, o células grandes con un núcleo lobulado "en grano de café", y un infiltrado de linfocitos, macrófagos y eosinófilos (Figura 9 a). En los pacientes estudiados con microscopía electrónica, se demostró los característicos gránulos de Birbeck al interior del citoplasma de las células de Langerhans (Figura 9 b), estas células fueron positivas para la tinción inmunohistoquímica antígeno de superficie CD-1A (Figura $9 \mathrm{c}$ ) y para la proteína S-100 (Figura $9 \mathrm{~d}$ ) en los casos estudiados.

Tabla II. Manifestaciones radiológicas de HCL.

\section{PATRON RADIOLOGICO}

$\begin{array}{lr}\text { Osteolítico } & 76,3 \\ \text { Permeativo } & 22,0 \\ \text { Vértebra plana } & 5,1 \\ \text { Reacción perióstica } & 50,8 \\ \text { Aumento de volumen } & \\ \text { de partes blandas } & 49,0\end{array}$
de partes blandas
(\%)

76,3

50,8

49,0
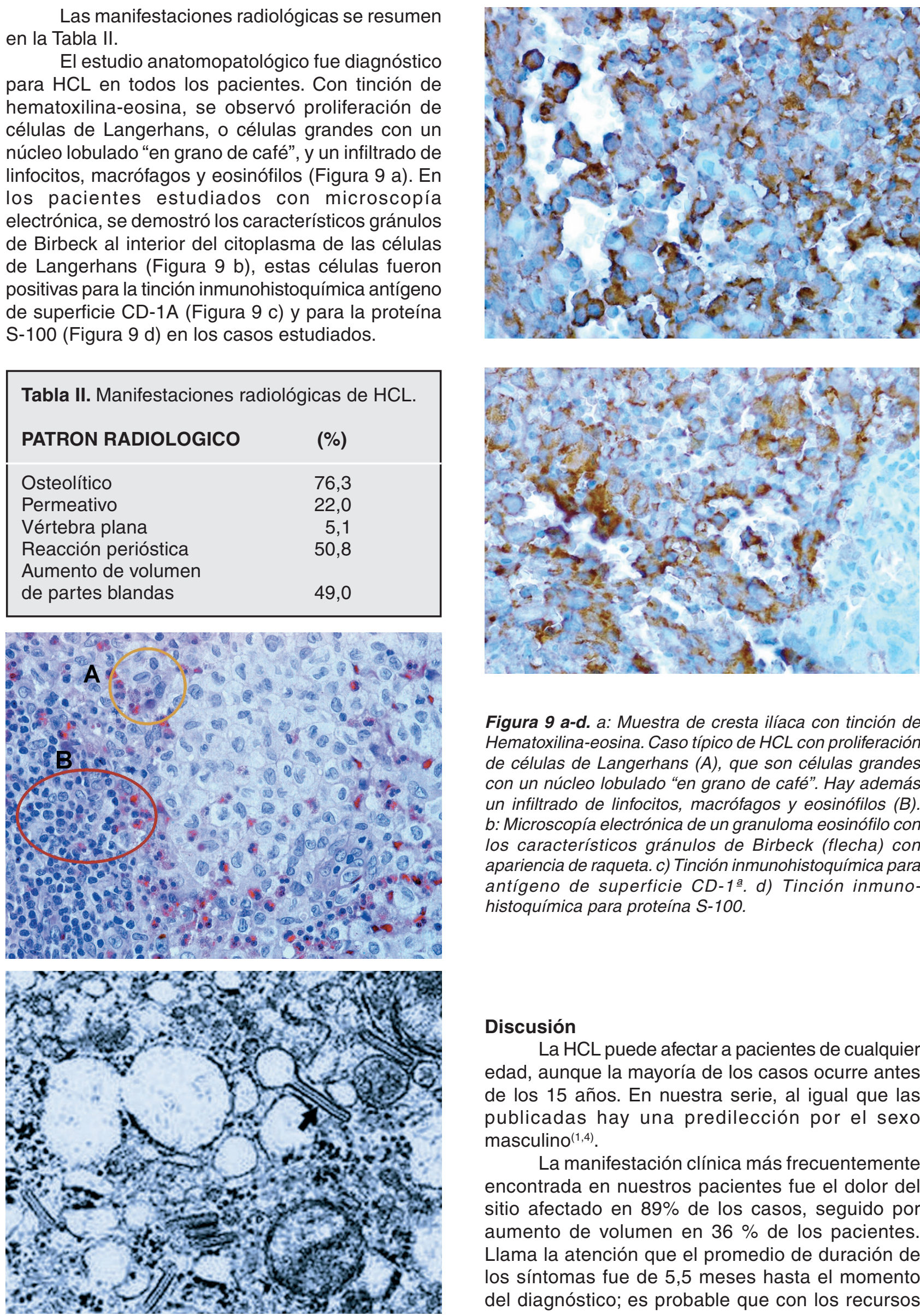

Figura 9 a-d. a: Muestra de cresta ilíaca con tinción de Hematoxilina-eosina. Caso típico de HCL con proliferación de células de Langerhans (A), que son células grandes con un núcleo lobulado "en grano de café". Hay además un infiltrado de linfocitos, macrófagos y eosinófilos (B). b: Microscopía electrónica de un granuloma eosinófilo con los característicos gránulos de Birbeck (flecha) con apariencia de raqueta. c) Tinción inmunohistoquímica para antígeno de superficie CD-1a. d) Tinción inmunohistoquímica para proteína S-100.

\section{Discusión}

La HCL puede afectar a pacientes de cualquier edad, aunque la mayoría de los casos ocurre antes de los 15 años. En nuestra serie, al igual que las publicadas hay una predilección por el sexo masculino ${ }^{(1,4)}$.

La manifestación clínica más frecuentemente encontrada en nuestros pacientes fue el dolor del sitio afectado en $89 \%$ de los casos, seguido por aumento de volumen en $36 \%$ de los pacientes. Llama la atención que el promedio de duración de los síntomas fue de 5,5 meses hasta el momento del diagnóstico; es probable que con los recursos 
de que disponemos en la actualidad ese tiempo se reduzca dramáticamente, así como también que aumente el número de casos encontrados de manera incidental.

En cuanto al patrón radiológico, éste depende del hueso afectado y de la fase de la enfermedad. Las lesiones agudas son generalmente osteolíticas, con bordes mal definidos, y es difícil diferenciarlas de osteomielitis, sarcoma de Ewing o linfoma. En huesos largos, el hallazgo inicial suele ser el de una pequeña lesión osteolítica, que puede regresar a una lesión bien definida de bordes escleróticos o bien progresar hacia la etapa crónica, con erosión de la cortical, reacción perióstica y/o aumento de volumen de partes blandas ${ }^{(8,10)}$

Las lesiones de la pared torácica comprendidas costillas, escápula y clavículas son osteolíticas, pueden ser expansivas y presentar además un aspecto permeativo (Figura 2). Por este motivo, una lesión destructiva costal única asociada a una masa de partes blandas puede confundirse con un sarcoma de Ewing ${ }^{(13)}$.

En el cráneo, las lesiones se desarrollan en el díploe, y son característicamente osteolíticas, redondeadas $u$ ovaladas, con bordes irregulares aunque bien definidos (Figuras 3 y 4 ); el compromiso asimétrico de la tabla externa e interna puede dar una apariencia biselada. Las lesiones líticas pueden ser confluentes, dando una apariencia "geográfica" (Figura 4). Puede verse un pequeño fragmento óseo al interior de la lesión, llamado "secuestro en botón", lo que también puede verse en infección incluyendo tuberculosis, quistes dermoides o epidermoides, osteoradionecrosis, y en defectos quirúrgicos en etapa de cicatrización. En el cráneo no se produce reacción perióstica.

La apariencia de "diente flotante" se ve en el compromiso mandibular o maxilar superior, secundaria a destrucción del hueso alveolar y de la lámina dura que rodea el diente.

En los huesos largos es frecuente la presentación como una lesión de tipo permeativo (Figura 5) o como un lesión osteolítica asociada a reacción perióstica y/o aumento de volumen de partes blandas (Figuras 6 y 7$)^{(8,10)}$.

En la columna vertebral, es más común el compromiso de la columna dorsal y en segundo lugar la columna lumbar. Suele haber compromiso de los cuerpos vertebrales, siendo poco frecuente la afectación de elementos posteriores y, excepcionalmente, de los discos intervertebrales. Tal como en nuestro estudio, el patrón más frecuente es el de vértebra plana (Figura 8), cuyo diagnóstico diferencial debe incluir metástasis, leucemia, linfoma, hemangioma o traumatismo(10). Habitualmente la altura del cuerpo vertebral se recupera tras la curación ${ }^{(14)}$.
A diferencia de los estudios extranjeros en que destaca el cráneo como el hueso más frecuentemente afectado, en nuestra serie fue el fémur, lo que probablemente es consecuencia de que la mayor parte de los médicos que derivan al Registro Nacional de Tumores Oseos eran traumatólogos y no neurocirujanos.

Planteado el diagnóstico de HCL es necesario descartar compromiso en otros sitios, para lo cual puede realizarse cintigrafía ósea con difosfonados o radiografías de todo el esqueleto. Es discutible si una técnica es mejor que la otra, muchos aconsejan considerarlas complementarias, pues hay estudios que demuestran que $19 \%$ de las lesiones no son visibles en la cintigrafía y $29 \%$ no lo son en la radiografía, particularmente lesiones costales de columna y pélvicas ${ }^{(15)}$. Lamentablemente, por el gran período de tiempo incluido en nuestro estudio, muchos de los pacientes no fueron evaluados sistemáticamente con alguna de las dos técnicas sino que, en general, sólo fueron estudiados los sitios sintomáticos.

Otros métodos de imágenes más sofisticados como la tomografía computarizada o la resonancia magnética (RM) son hoy día un complemento necesario, pues demuestran de mejor manera la anatomía de la lesión, su extensión dentro del hueso y el compromiso de las partes blandas. Esto es especialmente válido en las lesiones que comprometen la base del cráneo y la columna vertebral. En el caso de nuestros pacientes, la minoría de ellos, fueron sometidos a alguna de las dos técnicas, por la escasa o nula disponibilidad de ellas en el momento de estudio.

\section{Resumen y Conclusiones}

El patrón de presentación radiológica simple de la HCL puede ser variado, sin embargo, su diagnóstico debe ser sospechado por el médico radiólogo.

Creemos que esta revisión de 59 pacientes con diagnóstico histológico de $\mathrm{HCL}$ permite caracterizar las manifestaciones radiológicas óseas de esta enfermedad y es de utilidad en el enfrentamiento inicial y en el diagnóstico diferencial de una lesión ósea en el paciente pediátrico.

Si bien nuestros pacientes no fueron todos estudiados en forma sistemática con radiografías de todo el esqueleto, cintigrafía ósea, RM o TC, la radiografía simple sigue siendo el método de elección en el estudio inicial y, muchas veces, el único necesario para sugerir un diagnóstico y seguir una conducta adecuada.

\section{Bibliografía}

1. Egeler RM, D’Angio GJ. Langerhans cell histiocytosis. J Pediatr 1995; 127:1-11 
2. Favara BE, Feller AC, Pauli M Contemporary classification of histiocytic disorders. Med Pediatr Oncol 1997; 29: 157-166.

3. Berry DH, Gresik MV, Humphrey GB et al. Natural history of histiocytosis $\mathrm{X}$ : a pediatric oncology group study. Med Pediatr Oncol 1986; 14:1-5.

4. Meyer JS, Harty MP, Mahboubi S, et al. Langerhans cell histiocytosis: presentation and evolution of radiologic findings with clinical correlation. Radiographics 1995; 15: 1135-1146.

5. Chu T, Jaffe R. The normal Langerhans cell and the LCH cell. Br J Cancer 1994; 70 (suppl23): S4-S10.

6. Webb DKH. Histiocytic syndromes. En: LilleymanJ, Hann I, Blanchette V (eds) Pediatric Hematology, 2nd ed, 1999. Churchill Livingstone, London, pp356-361.

7. Willman CL. Detection of clonal histiocytes in Langerhans cell histiocytosis: biology and clinical significance. Br J Cancer 1994; 23: S29-S33.

8. Stull MA, Kransdorf MJ, Devaney KO. Langerhans cell histiocytosis of bone. Radiographics 1992; 12: 801-823.

9. Hutchinson RE, Uner AH. Pediatric neoplasia.
Morphology and biology. En: Parham DM (ed) Tumors of the Iymphoid organs. Lippincott - Raven, Philadelphia, pp 1996; 519-521.

10. Azouz EM, Sargal G, Rodríguez MM, Podda A. Langerhans cell histiocytosis: pathology, imaging and treatment of skeletal involvement. Pediatr Radiol 2005; 35: 103-115.

11. Fernandez-Latorre F, Menor-Serrano F, Alonso Charterina S, et al. Langerhans cell histiocytosis of the temporal bone in pediatric patients: imaging and follow-up. Am J Roentgenol AJR 2000; 174: 217-221.

12. Ugarriza FL, Cabezudo JM, Porras LF et al. Solitary eosinophilic granuloma of the cervicothoracic junction causing neurological deficit. Br J Neurosurg 2003; 17 : 178-181.

13. Jabra AA, Fisherman EK. Eosinophilic granuloma simulating an agressive rib neoplasm: CT evaluation. Pediatr Radiol 1992; 22: 447-448.

14. Sartorio DJ, Parker BR. Histiocytosis $X$ : rate and pattern of resolution of osseous lesions. Radiology 1984; 152: 679-684.

15. Conway JJ. Commentary. Pediatr Radiol 1996; 26 : 742-743.

Power Scribe de Dictaphone Co.

Software de administración de dictados y tanscripciones para Radiología

- Reconocimiento de voz en tiempo real.

- Rápida generación de un modelo de voz.

- Interfase de usuario Web.

- Integración con los principales sistemas PACS/RIS
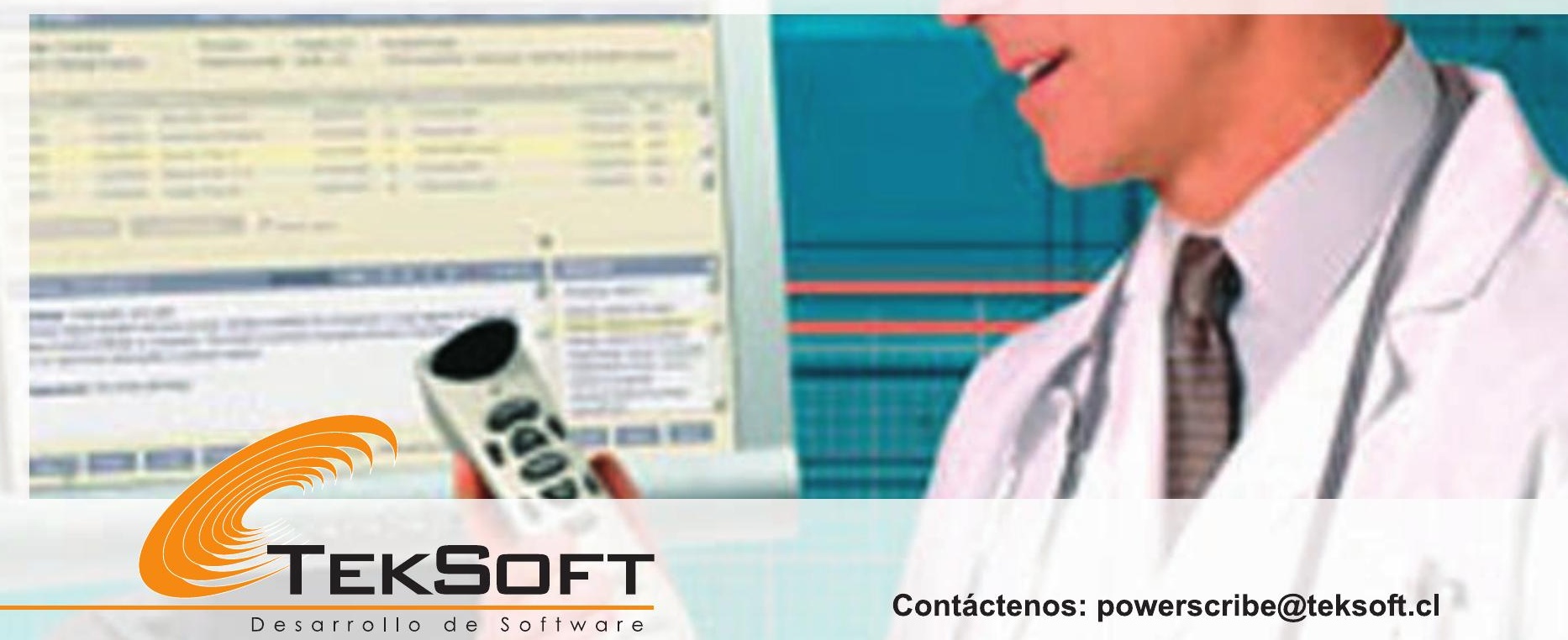

Contáctenos: powerscribe@teksoft.cl 